\title{
E-Commerce and SME Performance: The Moderating Influence of Entrepreneurial Competencies
}

\author{
Arsalan Hussain ${ }^{1}\left(\mathbb{D}\right.$, Minhas Akbar ${ }^{2,3, *(\mathbb{D})}$, Arfan Shahzad ${ }^{4}\left(\mathbb{D}\right.$, Petra Poulova $^{3, *(D)}$, Ahsan Akbar ${ }^{3,5}$ (D) \\ and Rohail Hassan ${ }^{4}$ (D) \\ 1 College of Business Management, Institute of Business Management, Karachi 75190, Pakistan; \\ arsalan.hussain@iobm.edu.pk \\ 2 Department of Management Sciences, COMSATS University Islamabad, Sahiwal Campus, \\ Sahiwal 57000, Pakistan \\ 3 Department of Informatics and Quantitative Methods, Faculty of Informatics and Management, University of \\ Hradec Kralove, 50003 Hradec Králové, Czech Republic; akbar@gcu.edu.cn \\ 4 Othman Yeop Abdullah Graduate School of Business (OYAGSB), Universiti Utara Malaysia, \\ Kuala Lumpur 50300, Malaysia; arfan@uum.edu.my (A.S.); rohail.hassan@uum.edu.my (R.H.) \\ 5 International Business School, Guangzhou City University of Technology, Guangzhou 510080, China \\ * Correspondence: minhasakbar@cuisahiwal.edu.pk (M.A); petra.poulova@uhk.cz (P.P.)
}

Citation: Hussain, Arsalan, Minhas Akbar, Arfan Shahzad, Petra Poulova, Ahsan Akbar, and Rohail Hassan. 2022. E-Commerce and SME Performance: The Moderating Influence of Entrepreneurial Competencies. Administrative Sciences 12: 13. https://doi.org/10.3390/ admsci12010013

Received: 10 November 2021 Accepted: 30 December 2021 Published: 18 January 2022

Publisher's Note: MDPI stays neutral with regard to jurisdictional claims in published maps and institutional affiliations.

Copyright: (C) 2022 by the authors. Licensee MDPI, Basel, Switzerland. This article is an open access article distributed under the terms and conditions of the Creative Commons Attribution (CC BY) license (https:// creativecommons.org/licenses/by/ $4.0 /)$.

\begin{abstract}
This research aims to examine the mediating role of the use of the e-commerce and moderating influence of entrepreneurial competencies on the performance of small and medium enterprises (SMEs). The study data were collected via a structured questionnaire comprised of a seven-point Likert scale from practitioners serving at the top and middle-level positions in Pakistani SMEs. The Partial Least Squares Structural Equation Modelling (PLS-SEM) technique was applied on 250 useable returned questionnaires. The results showed that the association between the use of ecommerce and firm performance is positively significant. Moreover, the use of e-commerce mediates the positive association between technological readiness, adoption cost, and firm performance. However, the moderating role of entrepreneurial competencies does not appear as significant between the use of e-commerce and manufacturing SMEs' performance. The present study is the first to explore entrepreneurial competencies as a moderator between e-commerce adoption and firm performance. The empirical outcomes of this research provide useful theoretical and practical implications for the managers and practitioners to understand the underlying factors for the successful implementation of e-commerce in the SME sector to enhance firm performance.
\end{abstract}

Keywords: e-commerce; entrepreneurial competencies; small and medium enterprises; technological readiness; adoption cost; resource-based view; diffusion of innovation; Pakistan

\section{Introduction}

Enterprise performance has gained considerable traction in recent years (Akbar et al. 2021a; Qureshi et al. 2021; Akbar et al. 2021b). Corporate performance is equally important to practitioners and academicians in the modern business era. Some researchers have analyzed firm performance broadly in terms of financial and non-financial indicators (Han and Hong 2019; Qureshi et al. 2021). However, corporate managers usually employ specific performance indicators such as sales increment, increased market return, investment growth, and return on investment on a year-to-year basis to measure financial performance (Combs et al. 2006; Rajan et al. 2007). Likewise, the firm's non-financial performance can be measured by customer satisfaction, advanced technological innovation, the perceived value of the product, employee satisfaction, and reduction in production time (Aziz et al. 2017; Fantazy et al. 2010).

In a similar context, small and medium enterprises' performances are a significant concern for industrialization and the growth of modern economies (Rajan et al. 2007; Shanmugam 2016), since it plays an imperative role in technological innovation in the context of 
business management (Nasuredin et al. 2016). In the modern business era, organizations increasingly push creativity and innovation to take advantage of new opportunities for successful business growth (Halim et al. 2015). Currently, multinational firms are concentrating on the industrial revolution 4.0 (Bousdekis et al. 2019). Likewise, digital technology has completely changed the operational process for small-scale industries. The global economy is moving towards the diverse advantages of Industry 4.0; the result is a higher quality of goods by lowering production costs by automation, artificial intelligence, and 3D printing innovations (Bousdekis et al. 2019). which would ultimately improve firm competitiveness. The rapid growth in technological innovation affects large- as well as small-scale industries.

Among the largest industries in Pakistan, considering total resources, it is not unreasonable to say that Pakistan's manufacturing industry is the country's leading sector. Manufacturing SMEs are considered the spin of the economy in Pakistan. According to Raza et al. (2017), SMEs contribute significantly to the economy of Pakistan, and $90 \%$ of all private enterprises are registered as SMEs. In Pakistan, the total number of registered businesses is around 3.2 million; approximately $90 \%$ of the businesses are covered under the definition of an SME (SMEDA 2018). Although developing countries' SMEs contribute to around 70\% of the GDP, SMEs' contributions to the GDP of the Pakistani economy is approximately $40 \%$ and lags behind their neighboring countries by around $30 \%$.

In addition, the manufacturing sector is an essential source of tax revenues and contributes to increasing several job opportunities for semi-skilled, skilled, and unskilled labor. Thus, the government of Pakistan has intensified focus on the advancement and development of the manufacturing industry. Four major categories fall under the manufacturing SMEs of Pakistan, namely, textile, leather, surgical instrument, and sports (Kazmi 2017). At times, the textile industry was the significant driver of the economy of Pakistan in terms of employment generation and country exports. However, the SME sector is severely affected by a lack of innovation capability and less focus on technological upgradation (Bilal et al. 2016). The share of textile SMEs in the global market has remained stagnant at $1.6 \%$

Similarly, the leather industry comprises four sub-sectors: garments, gloves, shoe uppers, and leather goods (Kazmi 2017). According to the Pakistan Tanner Association (PTA 2015), the leather industry earned 948 million USD yearly from its exports (Khan and Ali 2020). At present, the leather industry's export growth also had a negative change of 8.41 percent (EconomicSurvey 2019).

Likewise, sports goods SMEs play an essential role in the manufacturing sector. There is a broad category of sports products in manufacturing units such as polo sticks, hockey sticks, and cricket bats (Kazmi 2017). At present, the sports goods industry shows a negative growth of 9.04 percent in terms of exports (EconomicSurvey 2019). Lastly, the exporters and manufacturers of surgical instruments mainly deal with the surgical industries, veterinary instruments, dental instruments, tailor scissors, beauty salon instruments, manicure and pedicure items, and hairstylist scissors. Moreover, around 1900 SME surgical units produce a range of 10 to 500 products by using approximately 100,000 workers (The Financial Daily 2018). Presently, Pakistan's surgical instrument industry contributes 221.7 million USD in total exports of 2017-2018. However, in 2018-2019, Pakistani surgical SMEs experienced negative export growth (Pakistan Bureau of Statistics 2019).

Theoretically, previous researchers have examined the adoption of big data, usage of ERP (Yadegaridehkordi et al. 2020), use of e-government (Heredia-Calzado and Duréndez 2019), and use of e-marketing (Sheikh et al. 2018) as a mediator. Moreover, previous scholars have suggested developing a model using e-commerce adoption/usage as a mediating variable for developing countries (Hassen et al. 2019). Similarly, based on the RBV theory, entrepreneurial competency is also a valuable resource, and the theory argues that resources may eventually lead towards business success and performance (Kabir et al. 2017; Tehseen and Ramayah 2015). On the contrary, there is a dearth of research to explore the causal relationship between information communication technology (e-commerce) and productivity (DeStefano et al. 2018). These inconsistent results suggested a need to apply a moderator between the use of e-commerce and firm performance. Hence, in the present 
study, entrepreneurial competency is a moderator between Technological, organizational, and environmental (TOE) factors and the performance of SMEs. The first objective of this study is to examine the influence of TOE context factors on the use of e-commerce. Second, the paper examines to what extent does the use of e-commerce mediate the relationship between TOE factors and firm performance. Third, the study addresses the moderating role of entrepreneurial competencies between the use of e-commerce and SMEs' firm performance.

This article is further divided into four sections. Section 2 covers the compelling literature and development of the theoretical framework. In Section 3, the research design and its specific ingredients are discussed. Section 4 explains the analysis and results for identified hypotheses. Lastly, Section 5 concludes the present study and provides the limitations of this research paper.

\section{Literature Review}

\subsection{Technological Readiness and Use of E-Commerce}

Technological readiness is referred to as "the combination of IT infrastructure and IT human resources" (Zhu and Kraemer 2005). These resources are obligatory if organizations want to introduce e-commerce in their business operations (Caputo et al. 2019; Oliveira and Martins 2010a). Managers identify different choices to adopt technologies in their organizations. Similarly, it is also found by Zhu et al. (2003) that IT infrastructure and human skills of employees are two significant factors towards technological adoption. Thus, the combined effect of IT infrastructure and IT human resource expertise (technological readiness) needed further investigation. The previous literature depicts that the IT infrastructure and IT human skills' role significantly influences firm performance performance (Braojos et al. 2019; Caputo et al. 2019).

On the contrary, Hyung and Dedahanov (2014) examined that the association between technological innovation and performance is significantly weak. Hence, further investigation is required to explore IT infrastructure and IT experts' combined effect on e-commerce usage. Therefore, the hypothesis is proposed as follows:

Hypothesis 1. Technological readiness has a positive significant impact on the use of e-commerce.

\subsection{Adoption Cost and Use of E-Commerce}

The adoption of technology such as e-commerce needs some essential technological resources, for instance, IT infrastructure, internet network, software, hardware, and IT personnel. All of these necessities are quite expensive, particularly for small and medium firms. Moreover, cost remains a significant impediment in adopting/using technology, particularly for SMEs (Wymer and Regan 2015). Although the adoption cost of certain technological innovations also distresses the speed of technological adoption, in the present study, adoption costs included both initial technology usage and training costs to use that technology. Additionally, the adoption cost was considered essential for e-commerce usage (Domun and Bheemul 2019). Furthermore, the money or resources spend to adopt these technologies directly influence the speed of usage of that particular technology, especially in small businesses (Mohtaramzadeh et al. 2018). Therefore, there is a need to further investigate the adoption cost and the use of e-commerce.

Hypothesis 2. Adoption cost negatively influences the use of e-commerce.

\subsection{Government Support and Use of E-Commerce}

Government support means the encouraging businesses to use technology. Government support plays an essential role in making the industry policies effective (Manning et al. 2012), and in improving organizational innovativeness In developing countries such as China, the government has started many support programs by creating subsidiaries at different levels to support SMEs (Lin and Luan 2020). Governments mainly focus on 
large industry policies such as financial incentives criteria, and training and development programs to adopt new technologies (Merhi and Ahluwalia 2017). Thus, it is reasonable to further study the government support for SMEs, particularly for technological innovation such as the use of e-commerce. Therefore, the current study proposed the following hypothesis:

Hypothesis 3. Government support positively influences the use of e-commerce.

\subsection{Use of E-Commerce and Firm Performance}

In the digitization era, technological innovation is an essential element to be successful among competitors. Similarly, the adoption of technology such as e-commerce is changing the way businesses are conducted across the world (Sunayana and Parveen 2019). Hence, business operations are becoming more effective and competitive in the era of digital technology. Additionally, the literature highlights considerable evidence that e-commerce usage has a positive influence on the performances of small and medium industries (SMIs) by improving business processes (Wardoyo et al. 2018). Moreover, it is also investigated that e-commerce as a mediating variable needs future research to be better understood (Hassen et al. 2019). Likewise, the influence of e-business is also positive on organizational performance. Therefore, the present study posits the following hypothesis:

Hypothesis 4. The use of e-commerce is positively significant on the firm performance.

\subsection{Entrepreneurial Competencies Relationship with Firm Performance}

According to Boyatzis (1982) competencies related to managers have two broad dimensions. The first type is related to human behavior, which has twenty-one different types. The second type of competency has three dimensions such as traits, social roles, and skills. Based on the types mentioned above, managers have different capabilities that influence performance. By definition, the term entrepreneurial competencies refer to "entrepreneurs' overall sum of attributes such as beliefs, attitudes, skills, knowledge, personality, abilities behavioral tendencies and expertise needed for sustaining and successful entrepreneurship" (Kiggundu 2002).

Similarly, consistent with the above study, Gerli et al. (2011) concluded that entrepreneurial competency is directly related to business performance and result in higher entrepreneurial performance. Other authors also suggested that strategic factors such as entrepreneurial competencies significantly impact SME performance (Grimmer et al. 2017; Hashim et al. 2018). Therefore, the present study proposed the following hypothesis.

\section{Hypothesis 5. Entrepreneurial competencies have a significant influence on firm performance.}

\subsection{The Mediating Role of Use of E-Commerce between TOE Model and Firm Performance}

Technological resources are considered critical factors in the success of information systems (ISs) (Zain et al. 2005). According to previous researchers, technological readiness means combining two resources: IT human resource and IT infrastructure (Zhu and Kraemer 2005). Both are an essential part of firms' operations if the firm wants to use e-business (Oliveira and Martins 2010a). Similarly, Teo and Ranganathan (2004) also suggest that, if any firm adopts e-commerce, it will be more likely to improve its IT infrastructure. Likewise, Oliveira and Martins (2010b) also determine that companies without sufficient IT skills are less likely to adopt e-commerce in their operations.

Studies have emphasized that organizational factors correlate with business performance, particularly in SMEs (Bala and Feng 2019). Furthermore, Sila (2010) confirmed that e-commerce usage does not directly influence the firm's operational performance. However, it can enhance operational efficiency, which subsequently increases operational performance. Therefore, there is an extensive need to further study the adoption of technology as 
a mediator between organizational factors such as adoption cost and firm performance of SMEs.

Moreover, the implementation of technology such as electronic commerce is a difficult task without the government's support, particularly for SMEs. Similarly, the literature supports the positive correlation between government support and technology usage but the results are inconsistent. Therefore, to assess the impact of government support regarding technological adoption, there is a need for further empirical investigation. Additionally, government support positively affects firm performance (Han et al. 2017). Thus, the above discussion formulates the following hypotheses.

Hypothesis 6 . The use of e-commerce mediates the relationship between technological readiness and firm performance.

Hypothesis 7. The use of e-commerce mediates the relationship between adoption cost and firm performance.

Hypothesis 8. The use of e-commerce mediates the relationship between government support and firm performance.

\subsection{Entrepreneurial Competencies as a Moderator between the Use of E-Commerce and Firm Performance}

In previous literature, it was observed that small firms' performances are influenced by strategic factors of the organization such as entrepreneurial competencies (Grimmer et al. 2017). The RBV theory provides theoretical underpinning for entrepreneurial competencies as capabilities to obtain a competitive advantage and to enhance firm performance (Kabir et al. 2017). Moreover, it is also suggested that e-commerce has a significant influence on three different dimensions of performance: increased sales, efficiency and productivity, and coordination (Kraemer et al. 2005). On the contrary, there is no causal impact of technological innovation and productivity (DeStefano et al. 2018). Therefore, based on the above discussion, the present study has proposed a moderator between the use of e-commerce and firm performance.

Hypothesis 9. Entrepreneurial competencies positively moderate the relationship between the use of e-commerce and firm performance of SMEs.

\subsection{Theoretical Framework}

The theoretical foundation of the current study is based on the underlying principles of Resource Base View (RBV) theory provided by Barney in 1991. According to RBV, the competitive advantage for firms results from organizational resources that are valuable, unique, and difficult to imitate. Likewise, resources related to technological readiness and adoption cost are required to acquire certain technologies such as e-commerce to enhance the organizations system efficiency and to gain the advantages of technological readiness. However, government support is another significant factor that can drive firms to use e-commerce to continuously enhance firm performance with the help of entrepreneurial competency. However, the specific competencies of SMEs' entrepreneurs are essential for successfully identifying business opportunities.

Likewise, the DOI theory was introduced by Rogers in his book Diffusion of Innovation, which was first published in 1962, with a few more editions afterwards (1971, 1983, 1995, and 2003). Roger explained innovation as "an idea, practices, or object that is perceived to be new by an individual or another unit of adoption". The theory has supported technology usage studies (Mohtaramzadeh et al. 2018). Likewise, e-commerce has been applied in manufacturing SMEs to enhance efficiency and ultimately to achieve a competitive advantage over rivals. Therefore, based on DOI theory, technological adoption (e-commerce) towards firm performance is supported by DOI theory. 
In addition, in technological innovation studies, the TOE model is frequently used (Hussain et al. 2020). This theory says that firm structure should fit its organizational and environmental needs (Lawrence and Lorsch 1967). Afterwards, in 1990, Tornatzky and Fleischer emphasized that adopting technology in an enterprise is a multidimensional and critical decision influenced by several factors. In this framework, Tornatzky and colleagues identified and classified the factors into three contexts: TOE. The contexts above of the model act as an opportunity and/or constraint for "technological innovation".

Moreover, several studies have depicted the TOE framework with institutional theory theory (Oliveira and Martins 2010b; Zhu et al. 2006). For example, the adoption predictors in DOI include individual leader characteristics and internal organization characteristics that are compatible with the organizational context of the TOE. Likewise, the system openness in DOI is compatible with the TOE factors as shown in Figure 1. Finally, researchers implicitly emphasized that Rogers's innovation attributes are compatible with the technological context (Baker 2012; Zhu et al. 2006).

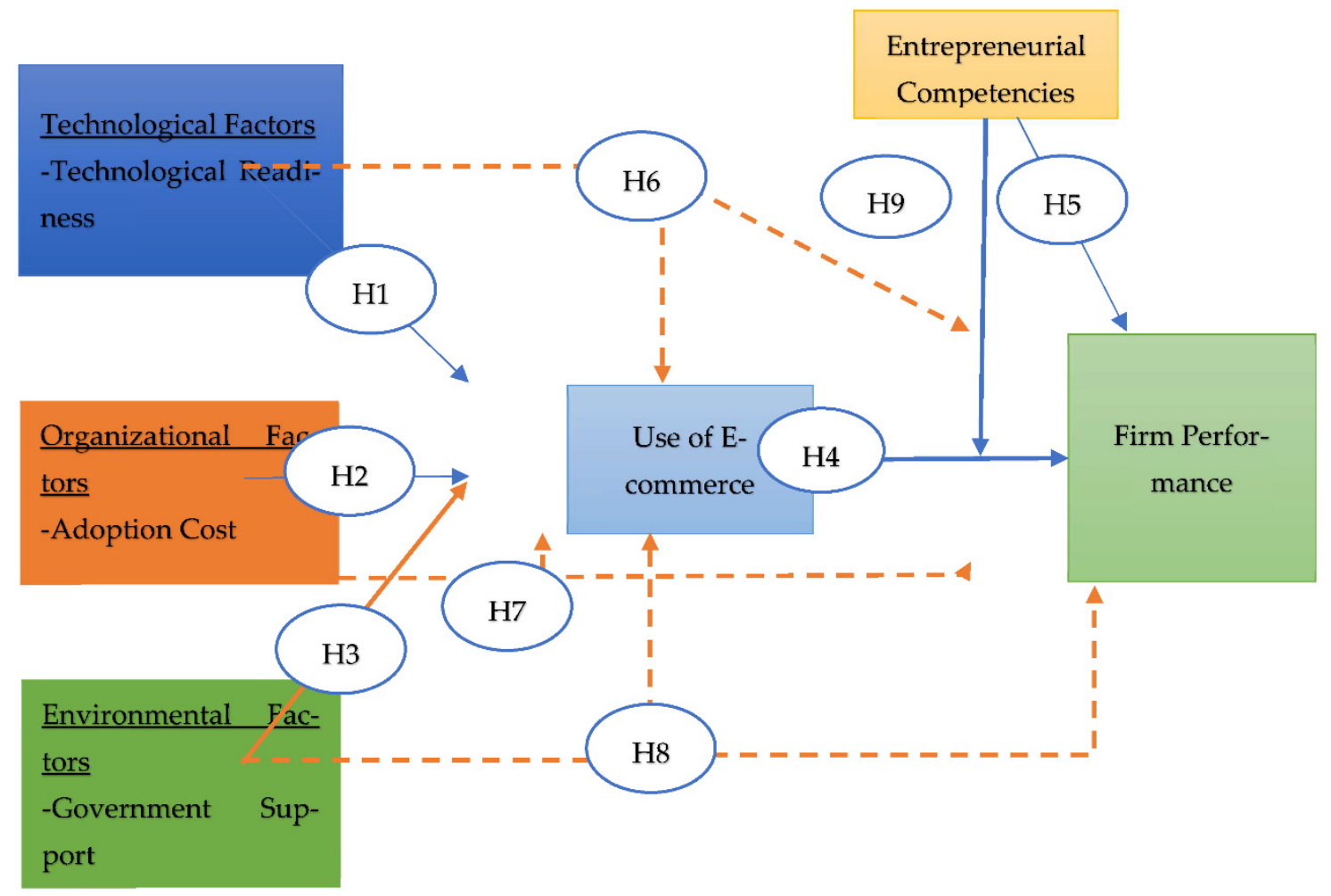

Figure 1. Theoretical framework.

It is indisputable that the use of e-commerce has grown as a popular research area for scholars since the 1990s, after the commercialization of the internet. However, Roger's Diffusion of innovation (DOI) theory has been used more frequently in e-commerce adoption studies (Al-Bakri and Katsioloudes 2015; Al-Qirim 2007). However, very few studies have looked into the Technology, Organizational, Environmental (TOE) model with DOI and RBV theories.

\section{Methodology}

\section{Research Design, Population, and Sampling Technique}

The research design combines research components into a reasonable, logical, and efficient method. Integrating an overall strategy by measuring and analyzing data ensures effective, credible, and systematic ways to resolve research problems and to answer research questions. The research design makes sure that the research questions are as accurately answered as possible by the data gathered for the research (Kumar 2019). 
In Pakistan, around 3.2 million businesses are registered; among them, approximately $90 \%$ of the companies are categorized into small and medium enterprises worldwide (SMEDA 2018). However, 254 manufacturing SMEs were selected by following the sample size table by Morgan (2012) using the "cluster random sampling technique". The population was divided into four clusters on the geographical distribution of provinces such as Sindh, Punjab, Balochistan, and Khyber Pakhtunkhwa. However, the Sindh and Punjab provinces were selected randomly because they have larger manufacturing SMEs. Therefore, six hundred (600) questionnaires were systematically sent via a Google Form link to the top and middle-level managers. The current study questionnaire was adapted from previous studies; the firm performance scale was adapted from (Deshpandé and Farley 1998; Jaworski and Kohli 1993). Likewise, seven items were adapted from the study conducted by Gibbs and Kraemer (2004) to measure the use of e-commerce; the questionnaire related to the technological readiness was adapted from Molla and Licker (2005) to measure top management support, the four-item scale by Soliman and Janz (2004) was adapted; and competitive pressure was measured using the Jaworski and Kohli (1993) questionnaire. Lastly, the moderating role of entrepreneurial competencies was measured using the four-item questionnaire from (Man et al. 2008).

This data collection took almost six and a half months, starting from May 2020 to December 2020. As mentioned in Table 1, 287 questionnaires were returned, out of which 37 questionnaires were not included in the analysis because they were incorrectly filled or incomplete. Thus, 250 questionnaires were used for the analyses.

Table 1. Questionnaire distribution and response rate.

\begin{tabular}{cc}
\hline Questionnaire & Response Rate \\
\hline Questionnaires distributed & 600 \\
\hline Number of questionnaires returned & 287 \\
\hline Questionnaires not matching the criteria & 21 \\
\hline Questionnaires, not complete & 16 \\
\hline Usable questionnaires & 250 \\
\hline Percentage of returned questionnaires & $47.8 \%$ \\
\hline Percentage of usable questionnaire & $41.6 \%$ \\
\hline
\end{tabular}

\section{Data Analysis and Findings}

The present study employed SPSS 25 to measure the descriptive statistics of the study. Similarly, for inferential statistics, the study used Structural Equation Modeling (SEM) by employing a Partial Least Square (PLS) 3.3.2 for data analysis purposes Sarstedt et al. (2017).

\subsection{Respondents' Profile}

Table 2 depicts a gender analysis of male participants with a response rate of $74.8 \%$ in the demographic analysis, while the female response rate was $25.2 \%$. In Pakistani Manufacturing SMEs, the age group of the managers revealed that $38.8 \%$ of the respondents are in the age bracket of 31-40 years. Lastly, the "Experience of using e-commerce" data verified that most of the managers who participated and had experience using e-commerce belong to the category 1 to 3 years. 
Table 2. Demographic analysis.

\begin{tabular}{ccc}
\hline $\begin{array}{c}\text { Demographics Respondents } \\
\text { Percentage (\%) }\end{array}$ & Frequency & Percentage \\
\hline Gender & 187 & 74.8 \\
\hline Male & 63 & 25.2 \\
\hline Female & & \\
\hline Age-Group & 63 & 25.2 \\
\hline $21-30$ years & 97 & 38.8 \\
\hline $31-40$ years & 90 & 36.0 \\
\hline More than 40 years & Experience Using E-Commerce & 26.0 \\
\hline Below 1 year & 65 & 41.2 \\
\hline Between 1 to 3 years & 103 & 32.8 \\
\hline More than 3 years & 82 & \\
\hline
\end{tabular}

\subsection{Assessment of Measurement Model}

Regarding the assessment of the measurement model, also termed the outer model, the present study analyzed the discriminate validity and internal consistency reliability (Hair et al. 2013), as shown in Figure 2.

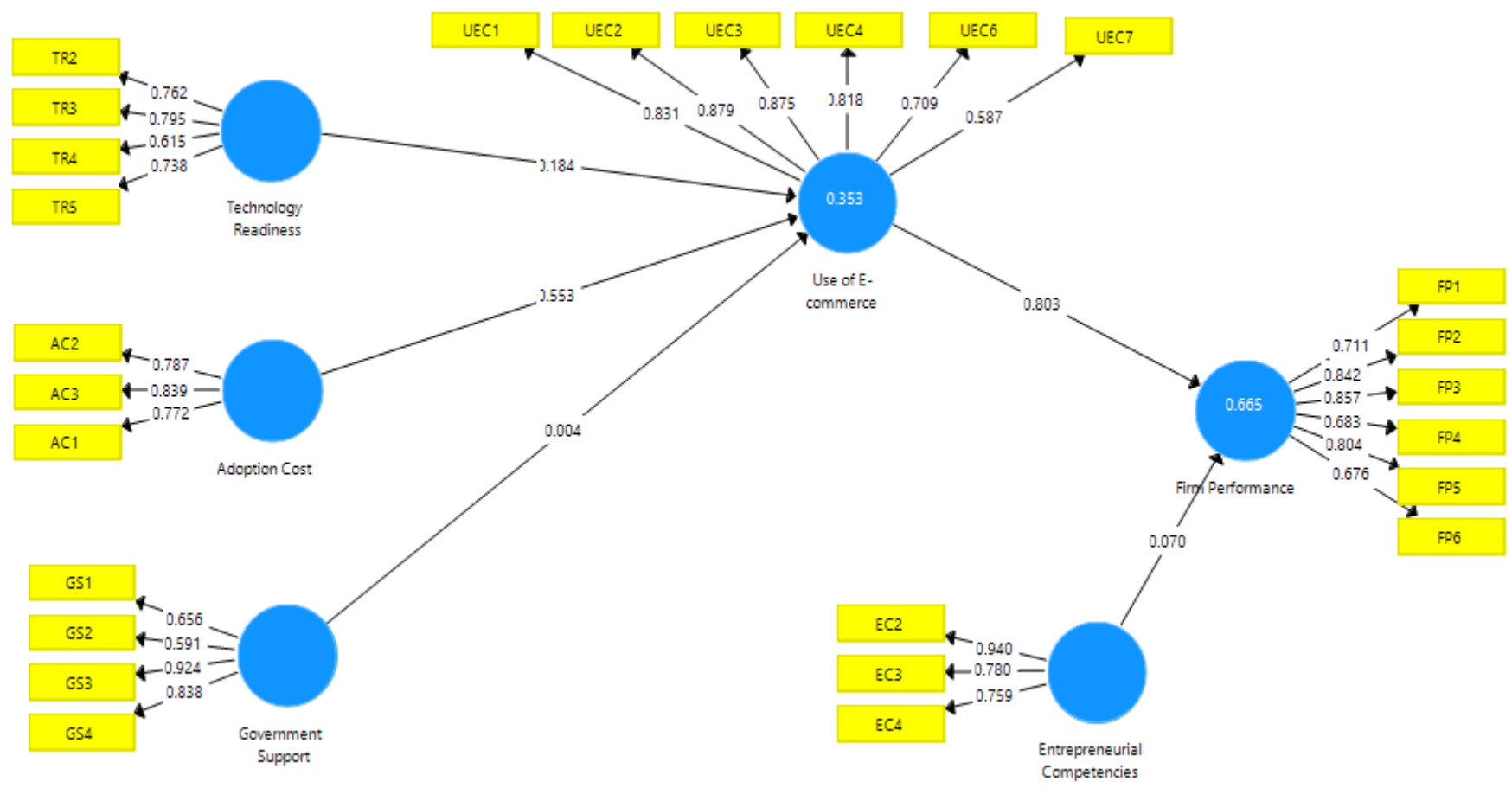

Figure 2. PLS algorithm measurement model.

\subsubsection{Internal Consistency Reliability and Convergent Validity}

The internal reliability can be determined by considering the composite reliability (CR) of the constructs. Table 3 predicted that all of the CR values are above the standard value 0.60 Hair et al. (2013). The convergent validity (CR) was explained by Hair et al. (2013) as "the degree to which a latent construct explains the variance of its indicators". Moreover, $50 \%$ of the variance should be achieved by each construct (AVE $\geq 0.50$ ). The following Table 3 depicted that the values are higher than 0.05. Furthermore, the cross-loading of 
each construct must be higher than 0.05 (Hair et al. 2013). The following table reveals that all of the values of loading are between the rage of 0.646 and 0.955 .

Table 3. Reliability and validity of the constructs.

\begin{tabular}{|c|c|c|c|c|}
\hline Construct & Items & Loadings & $\begin{array}{c}\text { Composite } \\
\text { Reliability (CR) }\end{array}$ & $\begin{array}{l}\text { Average Variance } \\
\text { Extracted (AVE) }\end{array}$ \\
\hline \multirow[t]{3}{*}{ Adoption Cost } & AC1 & 0.772 & 0.842 & 0.639 \\
\hline & AC2 & 0.787 & & \\
\hline & AC3 & 0.839 & & \\
\hline \multirow[t]{3}{*}{$\begin{array}{c}\text { Entrepreneurial } \\
\text { Competencies }\end{array}$} & $\mathrm{EC} 2$ & 0.940 & 0.868 & 0.689 \\
\hline & EC3 & 0.780 & & \\
\hline & EC4 & 0.759 & & \\
\hline \multirow[t]{6}{*}{$\begin{array}{c}\text { Firm } \\
\text { Performance }\end{array}$} & FP1 & 0.711 & 0.894 & 0.586 \\
\hline & FP2 & 0.842 & & \\
\hline & FP3 & 0.857 & & \\
\hline & FP4 & 0.683 & & \\
\hline & FP5 & 0.804 & & \\
\hline & FP6 & 0.676 & & \\
\hline \multirow[t]{4}{*}{$\begin{array}{l}\text { Government } \\
\text { Support }\end{array}$} & GS1 & 0.656 & 0.845 & 0.584 \\
\hline & GS2 & 0.591 & & \\
\hline & GS3 & 0.924 & & \\
\hline & GS4 & 0.838 & & \\
\hline \multirow[t]{4}{*}{$\begin{array}{l}\text { Technological } \\
\text { Readiness }\end{array}$} & TR2 & 0.762 & 0.819 & 0.534 \\
\hline & TR3 & 0.795 & & \\
\hline & TR4 & 0.615 & & \\
\hline & TR5 & 0.738 & & \\
\hline \multirow[t]{6}{*}{$\begin{array}{c}\text { Use of } \\
\text { E-commerce }\end{array}$} & UEC1 & 0.831 & 0.907 & 0.624 \\
\hline & UEC2 & 0.879 & & \\
\hline & UEC3 & 0.875 & & \\
\hline & UEC4 & 0.818 & & \\
\hline & UEC6 & 0.709 & & \\
\hline & UEC7 & 0.587 & & \\
\hline
\end{tabular}

\subsubsection{Discriminate Validity}

The discriminate validity was checked by applying Fornell and Larcker's criteria. It is explained as "the extent to which the constructs are different from one another empirically". According to Fornell and Larker's criteria of discrimination validity, the current results suggest that constructs do not explain a similar phenomenon. Thus, Table 4 below explains that the square root of AVE is higher than the correlation between the latent variables (Fornell and Larcker 1981). 
Table 4. Discriminate validity matrix.

\begin{tabular}{ccccccc}
\hline & AC & EC & FP & GS & TR & UEC \\
\hline AC & 0.800 & & & & & \\
\hline EC & 0.123 & 0.830 & & & & \\
\hline FP & 0.467 & 0.177 & 0.766 & & & \\
\hline GS & 0.040 & -0.045 & 0.100 & 0.764 & & \\
\hline TR & 0.064 & 0.068 & 0.155 & 0.400 & 0.731 & \\
\hline UEC & 0.565 & 0.133 & 0.812 & 0.099 & 0.221 & 0.790 \\
\hline
\end{tabular}

\subsection{Assessment of Structural Model}

Table 5 mentioned that one out of five hypotheses is not supported based on the standard $p$ value (0.05). The structural model elaborates the direct effect of the relationships and the $t$-value and $p$-value to show the hypotheses' significance. Moreover, the study also applied a bootstrapping technique to analyze the indirect (mediation) relationship with e-commerce between exogenous and endogenous variables, as shown in Figure 3.

Table 5. Hypothesis testing results (direct effect).

\begin{tabular}{ccccccccccccc}
\hline No. & Relationship & $\begin{array}{c}\text { Std. } \\
\text { Beta }\end{array}$ & $\begin{array}{c}\text { Std. } \\
\text { Error }\end{array}$ & $\boldsymbol{T}$ Values & $p$ Values & $\mathbf{0 . 0 2 5}$ & $\mathbf{0 . 9 7 5}$ & Decision & VIF & F Square & $\mathbf{R}^{\mathbf{2}}$ & $\mathbf{Q}^{\mathbf{2}}$ \\
\hline H1 & AC $\rightarrow$ UEC & 0.55 & 0.04 & 12.43 & 0.000 & 0.473 & 0.620 & Supported & 1.004 & 0.471 & 0.665 & 0.386 \\
\hline H2 & TR $\rightarrow$ UEC & 0.18 & 0.05 & 3.23 & 0.001 & 0.087 & 0.273 & Supported & 1.194 & 0.044 & \\
\hline H3 & GS $\rightarrow$ UEC & 0.00 & 0.06 & 0.05 & 0.479 & -0.17 & 0.080 & Not Supported & 1.191 & 0.000 & \\
\hline H4 & UEC $\rightarrow$ FP & 0.78 & 0.02 & 31.23 & 0.000 & 0.752 & 0.833 & Supported & 1.046 & 1.811 & \\
\hline H5 & EC $\rightarrow$ FP & 0.07 & 0.03 & 1.95 & 0.025 & 0.013 & 0.141 & Supported & 1.026 & 0.018 & 0.353 & 0.216 \\
\hline
\end{tabular}

Note: TR $=$ Technological Readiness, $\mathrm{AC}=$ Adoption Cost, GS = Government Support, UEC $=$ Use of E-commerce EC $=$ Entrepreneurial Competencies, FP = Firm Performance.

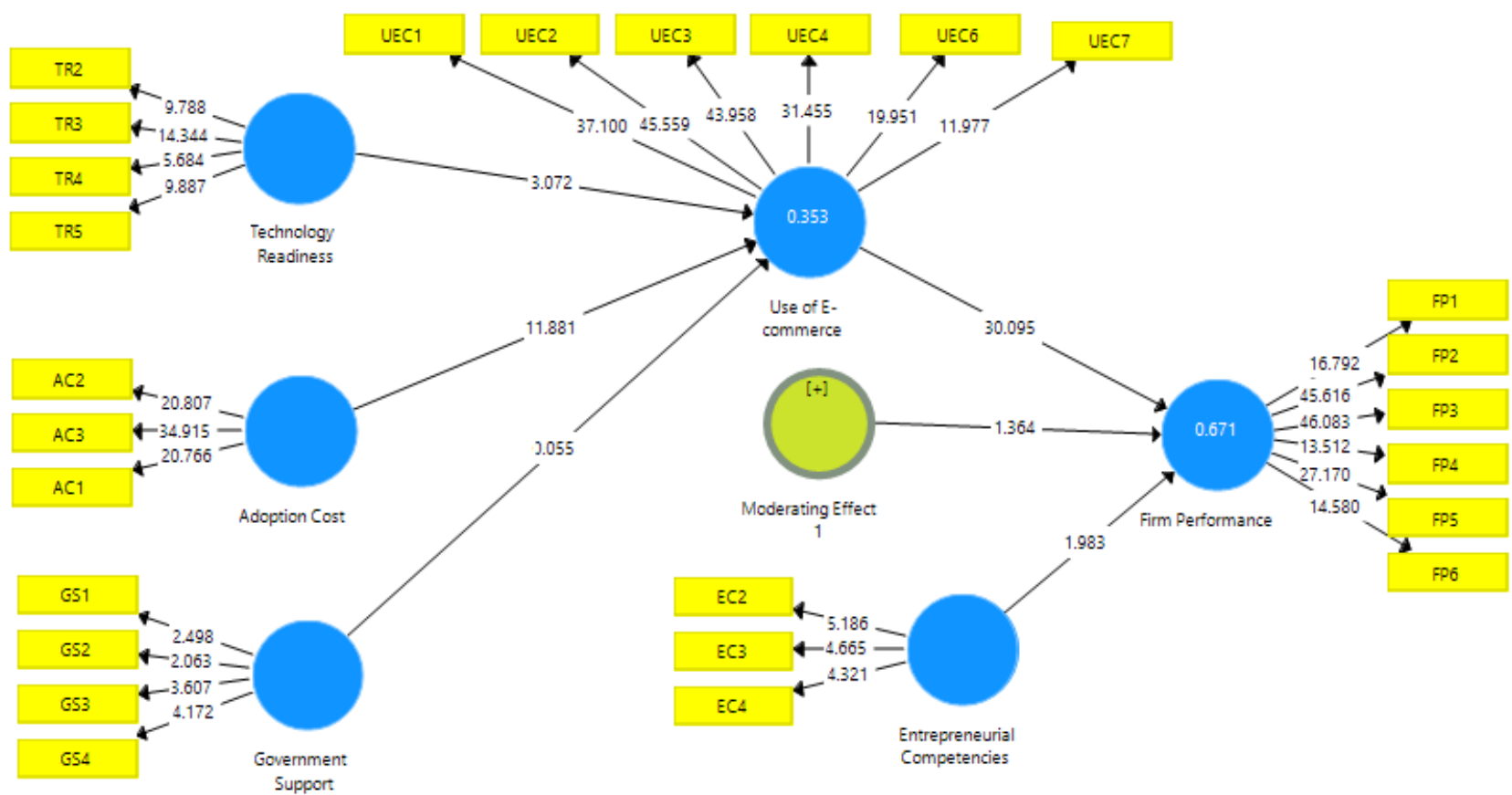

Figure 3. The structural model and moderating effect.

The result indicates that $\mathrm{H} 1(\beta=0.553 ; T=12.432 ; p<0.05)$ and $\mathrm{H} 2(\beta=0.184$; $T=3.238 ; p<0.05)$ show that a significant association between adoption cost, technological 
readiness, and use of e-commerce. Similarly, $\mathrm{H} 4(\beta=0.077 ; T=1.957 ; p<0.050 .05)$ and H5 $(\beta=0.789 ; T=31.237 ; p<0.05)$ show the significant positive link between entrepreneurial competencies and use of e-commerce with SME performance. However, H3 ( $\beta=0.004$; $T=0.053 ; p>0.05$ ) empirically shows that government support has no significant impact on the use of e-commerce.

Assessment of Coefficient of Determination $\left(\mathrm{R}^{2}\right)$, Effect Size $\left(\mathrm{f}^{2}\right)$, and Predictive Relevance $\left(Q^{2}\right)$

The coefficient of determination, denoted by $R^{2}$, explains how much variation in the endogenous variable is due to exogenous constructs. It is also considered a criterion used to assess the structural model. Nevertheless, in this study, $R^{2}$ at 0.618 is substantial. However, the coefficient of determination $R^{2}$ for the use of e-commerce stood at 0.051 , which shows weakness as per the standards. After the analysis of the coefficient of determination $\left(R^{2}\right)$, there is a need to examine the effect size $\left(\mathrm{f}^{2}\right)$ of all of the latent variables of the study. The $\mathrm{f}^{2}$ threshold values are $0.35,0.15$, and 0.02 for large, small, and no effect size, respectively; in this study, the effect size values show small and no effects, with values of $0.028,0.005$, $0.019,0.593$, and 0.002 .

Likewise, the study used the blindfolding method to assess the model's predictive relevance $\left(Q^{2}\right)$ ability. As shown in Table 5, the $Q^{2}$ values are higher than zero for use of e-commerce (0.216) and firm performance (0.386); this suggests a substantial predictive relevance of the model. This is in line with the suggestion by Henseler and Hubona that $Q^{2}$ values greater than zero indicate that the model has predictive relevance while $\mathrm{Q}^{2}$ values less than zero indicate that the model lacks predictive relevance.

\subsection{Mediation Analysis}

Among the various methods used to test the mediation, the most commonly used technique is bootstrapping.

In this study, bootstrapping is applied to examine the latent variables' indirect effect by using 5000 subsamples. Table 6 summarizes the result of the indirect relationships of the model.

Table 6. Mediation results.

\begin{tabular}{cccccccccc}
\hline \multicolumn{2}{c}{ Mediation Result } & Std. Beta & Std. Error & $\boldsymbol{T}$ Values & $\boldsymbol{p}$-Values & $\mathbf{2 . 5 0 \%}$ & $\mathbf{9 7 . 5 0 \%}$ & Decision \\
\hline $\mathrm{H} 6$ & $\mathrm{TR} \rightarrow \mathrm{UEC} \rightarrow$ FP & 0.148 & 0.045 & 3.260 & 0.001 & 0.070 & 0.216 & Supported \\
\hline $\mathrm{H} 7$ & $\mathrm{AC} \rightarrow \mathrm{UEC} \rightarrow$ FP & 0.432 & 0.039 & 11.122 & 0.000 & 0.374 & 0.500 & Supported \\
\hline $\mathrm{H} 8$ & $\mathrm{GS} \rightarrow \mathrm{UEC} \rightarrow$ FP & 0.010 & 0.053 & 0.053 & 0.479 & -0.133 & 0.064 & Not Supported \\
\hline
\end{tabular}

Note: TR = Technological Readiness, AC = Adoption Cost, GS = Government Support, UEC = Use of E-commerce, FP $=$ Firm Performance.

Therefore, the results of H6 $(\beta=0.148 ; T=3.260 ; p<0.05)$ and H7 $(\beta=0.432 ; T=11.122$; $p<0.05)$ show that the positive relationship between technological readiness, adoption cost, and firm performance is mediated by the use of e-commerce. These results indicate that $\mathrm{H} 6$ and $\mathrm{H} 7$ are supported. The result of $\mathrm{H} 8(\beta=0.010 ; T=0.053 ; p>0.05)$ suggests that the use of e-commerce does not mediate the relationship between government support and firm performance.

\subsection{Moderation Analysis}

In the moderating effect analysis, we used the PLS algorithm to calculate the standard beta coefficient value, which was 0.084 for entrepreneurial competencies. Likewise, to calculate the $T$-value result, we followed a bootstrapping procedure. Table 7 shows that entrepreneurial competencies do not significantly moderate the relationship between the use of e-commerce and manufacturing SMEs' performances. 
Table 7. Moderation result.

\begin{tabular}{ccccccccc}
\hline No. & Relationship & Std. Beta & Std. Error & T Values & $p$ Values & $\mathbf{2 . 5 0 \%}$ & $\mathbf{9 7 . 5 \%}$ & Decision \\
\hline H9 & $\begin{array}{c}\text { Moderating Effect } 1 \\
\rightarrow \text { Firm Performance }\end{array}$ & 0.084 & 0.060 & 1.413 & 0.079 & -0.101 & 0.146 & Not Supported \\
\hline
\end{tabular}

\section{Discussion and Conclusions}

The primary purpose of a discussion is to assess whether the outcomes of the study are consistent with the objectives of the study. The present study provided a theoretical framework to examine technological (technological readiness), organizational (adoption cost), and environmental factors (government support) of the TOE model with the mediating effect of the use of e-commerce on firm performance. The study also employed a moderating role of entrepreneurial competencies. The theoretical foundations of the study are based on a resource-based view and the Diffusion of innovation (DOI).

To achieve the objectives of the study, eight hypotheses were formulated for empirical testing. Four out of five hypotheses were supported, to be specific, in terms of a direct relationship. One out of three hypotheses was not supported in the mediating effect of the relationships. The direct hypotheses reveals that technological readiness has a significant relationship with SME performance, consistent with the previous study (Alsultanny and AlZuhair 2018). Therefore, the findings suggest that the technological infrastructure and IT human skills are necessary elements to implement. Although, in the literature, cost remains a significant impediment for the use of technological innovation, particularly for SMEs (Wymer and Regan 2015), as per the findings of the current study, adoption cost has a significant relationship with the use of e-commerce in manufacturing SMEs of developing countries such as Pakistan.

Furthermore, the hypotheses regarding the effect of government support on the use of e-commerce results are not consistent with the previous literature (Han et al. 2017). In the present study, government support has appeared as an insignificant factor for the use of e-commerce. This proved that there is less government support for the use of e-commerce in Pakistani manufacturing SMEs. However, the study results are consistent with previous literature on the use of e-commerce and firm performance relationships (Braojos et al. 2019; Shahzad et al. 2020).

Regarding the indirect effects (mediation analyses), e-commerce usage mediation has a significant relationship with technological readiness and adoption cost. The current study concluded that, through the mediation of the use of e-commerce technology, readiness and adoption cost could enhance the performance of manufacturing SMEs of Pakistan. However, government support is not an influencing factor in Pakistani manufacturing SMEs.

Lastly, this study finds that entrepreneurial competencies have an insignificant relationship as a moderator between the use of e-commerce and firm performance. The empirical evidence of the study showed that entrepreneurial competencies do not positively impact firm performance. Therefore, the present study concluded that, instead of owner competencies such as negotiation skills, long-term relationships with other business partners, and market-related skills, SME managers/owners need technology-related competencies and more knowledge about e-commerce platforms to obtain a competitive advantage. Moreover, with the theoretical foundation of the RBV, the study found that entrepreneurial competencies are not considered long-term capabilities for manufacturing SMEs of Pakistan.

\subsection{Implications of the Study}

Besides technological, organizational, and environmental factors directly linked with the use of e-commerce, this study goes beyond the tested mediation present among the TOE context factors and firm performance. In addition to the mediation, the moderating role of entrepreneurial competencies served as capabilities between e-commerce and firm performance. For the first time in the literature, this link has been established between the 
use of e-commerce and firm performance using the resource-based view (RBV) theory. As a result, the present study has contributed theoretically to the literature and serves to enhance the pool of knowledge and understanding. Therefore, this study provides progressive insight into issues related to the use of e-commerce and ultimately to firm performance.

Moreover, the significant direct and indirect relationships with the use of e-commerce also call upon the SME managers' attentions towards the availability of such resources (independent variables) before implementing e-commerce in their organizations. Hence, this study has tried to explain the essential underlying factors and capabilities required to convert the firm from a traditional way of conducting business to a click and mortar business using e-commerce.

\subsection{Limitations and Future Recommendation}

The implications of the current study are only useful for manufacturing SMEs of Pakistan. Similar research can be conducted in other developing countries by taking the same theoretical foundations. Furthermore, the study model can be useful for retail and service sector SMEs. Moreover, future research can investigate the innovation capabilities, open innovation, and business model innovation as mediators with the theoretical foundation of the TOE model and dynamic capability theory.

\subsection{Conclusions of the Study}

To sum up, this study requires SME practitioners to develop a modern e-commerce infrastructure to increase performance. Top management and entrepreneurs need to build their competencies and to focus on commission-based cloud platforms of e-commerce for their future growth. Likewise, the government's role should be to invest in the technological infrastructure for robust internet connectivity in urban and rural areas. Furthermore, to promote e-commerce platforms for SMEs. Furthermore, the present study requires SME owners to look at technological readiness, adoption cost, and entrepreneurial competencies to achieve optimal benefits by implementing e-commerce.

Author Contributions: Conceptualization, A.H. and A.S.; methodology, A.S. and R.H.; validation, M.A., A.S. and R.H.; writing—original draft preparation, A.H. and A.A.; writing-review and editing, A.H., P.P. and R.H.; visualization, P.P., A.S. and R.H.; supervision, A.S., M.A. and R.H. All authors have read and agreed to the published version of the manuscript.

Funding: The open access fee of this research was supported by the SPEV project 2021 at the Faculty of Informatics and Management, University of Hradec Kralove, Czech Republic.

Institutional Review Board Statement: Not applicable.

Informed Consent Statement: Not applicable.

Data Availability Statement: Data are available from the authors and can be provided upon request.

Conflicts of Interest: The authors declare no conflict of interest.

\section{References}

Akbar, Ahsan, Xinfeng Jiang, Muhammad Azeem Qureshi, and Minhas Akbar. 2021a. Does Corporate Environmental Investment Impede Financial Performance of Chinese Enterprises? The Moderating Role of Financial Constraints. Environmental Science and Pollution Research 28: 58007-17. [CrossRef] [PubMed]

Akbar, Minhas, Ahsan Akbar, and Muhammad Umar Draz. 2021b. Global Financial Crisis, Working Capital Management, and Firm Performance: Evidence from an Islamic Market Index. SAGE Open 11: 21582440211015705. [CrossRef]

Al-Bakri, Anas A., and Marios I. Katsioloudes. 2015. The Factors Affecting E-Commerce Adoption by Jordanian Smes. Management Research Review 38: 726-49. [CrossRef]

Al-Qirim, Nabeel. 2007. The Adoption of Ecommerce Communications and Applications Technologies in Small Businesses in New Zealand. Electronic Commerce Research and Applications 6: 462-73. [CrossRef]

Alsultanny, Yas, and Sara AlZuhair. 2018. Evaluating Influence of Technology Readiness Factors on the Saudi Cement Companies Market and Financial Based Performance. Journal of Science and Technology Policy Management. [CrossRef] 
Aziz, Khurram, Syed Shahbaz Ul Hasnain, Muhammad Awais, Iram Shahzadi, and Muhammad Moeiz Afzal. 2017. The Impact of Entrepreneurial Orientation on Sme Performance in Pakistan: A Qualitative Analysis. International Journal of Engineering and Information Systems (IJEAIS) 1: 107-12.

Baker, Richard W. 2012. Membrane Technology and Applications. West Sussex: John Wiley \& Sons.

Bala, Hillol, and Xuan Feng. 2019. Success of Small and Medium Enterprises in Myanmar: Role of Technological, Organizational, and Environmental Factors. Journal of Global Information Technology Management 22: 100-19. [CrossRef]

Bilal, Ahmad Raza, Aaisha Arbab Khan, and Michèle Eunice Marie Akoorie. 2016. Constraints to Growth: A Cross Country Analysis of Chinese, Indian and Pakistani Smes. Chinese Management Studies 57: 2032-51. [CrossRef]

Bousdekis, Alexandros, Dimitris Apostolou, and Gregoris Mentzas. 2019. Predictive Maintenance in the 4th Industrial Revolution: Benefits, Business Opportunities, and Managerial Implications. IEEE Engineering Management Review 48: 57-62. [CrossRef]

Boyatzis, R. E. 1982. The Competent Manager: A Model for Effective Performance. West Sussex: John Wiley \& Sons.

Braojos, Jessica, Jose Benitez, and Javier Llorens. 2019. How Do Social Commerce-It Capabilities Influence Firm Performance? Theory and Empirical Evidence. Information \& Management 56: 155-71.

Caputo, Francesco, Valentina Cillo, Elena Candelo, and Yipeng Liu. 2019. Innovating through Digital Revolution: The Role of Soft Skills and Big Data in Increasing Firm Performance. Management Decision. [CrossRef]

Combs, James, Yongmei Liu, Angela Hall, and David Ketchen. 2006. How Much Do High-Performance Work Practices Matter? A Meta-Analysis of Their Effects on Organizational Performance. Personnel Psychology 59: 501-28. [CrossRef]

Deshpandé, Rohit, and John U. Farley. 1998. Measuring Market Orientation: Generalization and Synthesis. Journal of Market-Focused Management 2: 213-32. [CrossRef]

DeStefano, Timothy, Richard Kneller, and Jonathan Timmis. 2018. Broadband Infrastructure, Ict Use and Firm Performance: Evidence for Uk Firms. Journal of Economic Behavior E Organization 155: 110-39.

Domun, V., and H. Bheemul. 2019. Factors Affecting the Adoption of Cloud Computing among Smes in Mauritius. In Information Systems Design and Intelligent Applications. Singapore: Springer, pp. 333-36. [CrossRef]

EconomicSurvey. 2019. Economic Survey of Pakistan. Islamabad: Finance division, Governmnet of Pakistan, Available online: http:/ / hdl.handle.net/123456789/17014 (accessed on 28 September 2021).

Fantazy, Kamel A., Vinod Kumar, and Uma Kumar. 2010. Supply Management Practices and Performance in the Canadian Hospitality Industry. International Journal of Hospitality Management 29: 685-93. [CrossRef]

Fornell, C., and D. F. Larcker. 1981. Evaluating structural equation models with unobservable variables and measurement error. Journal of Marketing Research 18: 39-50. [CrossRef]

Gerli, Fabrizio, Paolo Gubitta, and Alessandra Tognazzo. 2011. Entrepreneurial Competencies and Firm Performance: An Empirical Study. Paper presented at the VIII International Workshop on Human Resource Management, Sevilla, Spain, May 12-13.

Gibbs, Jennifer L., and Kenneth L. Kraemer. 2004. A Cross-Country Investigation of the Determinants of Scope of E-Commerce Use: An Institutional Approach. Electronic Markets 14: 124-37. [CrossRef]

Grimmer, Louise, Morgan P. Miles, John Byrom, and Martin Grimmer. 2017. The Impact of Resources and Strategic Orientation on Small Retail Firm Performance. Journal of Small Business Management 55: 7-26. [CrossRef]

Hair, Joseph F., Christian M. Ringle, and Marko Sarstedt. 2013. Partial Least Squares Structural Equation Modeling: Rigorous Applications, Better Results and Higher Acceptance. Long Range Planning 46: 1-12. [CrossRef]

Halim, Hasliza Abdul, Noor Hazlina Ahmad, T. Ramayah, Haniruzila Hanifah, Seyedeh Khadijeh Taghizadeh, and Marini Nurbanum Mohamad. 2015. Towards an innovation culture: Enhancing innovative performance of Malaysian SMEs. Academic Journal of Interdisciplinary Studies 4: 85.

Han, Yoo Jin, Jee Yong Chung, Jong Seo Son, and Sang Jib Kwon. 2017. The Effects of the Innovation Types of Venture Firms and Government Support on Firm Performance and New Job Creation: Evidence from South Korea. Academy of Strategic Management Journal 16: 1-14.

Han, Yousueng, and Sounman Hong. 2019. The Impact of Accountability on Organizational Performance in the Us Federal Government: The Moderating Role of Autonomy. Review of Public Personnel Administration 39: 3-23. [CrossRef]

Hashim, Noor Azmi Bin, Saqlain Raza, and Mohd Sobri Minai. 2018. Relationship between Entrepreneurial Competencies and Small Firm Performance: Are Dynamic Capabilities the Missing Link? Academy of Strategic Management Journal 17: 1-10.

Hassen, Houache, Noor Hayani Abd Rahim, and Asadullah Shah. 2019. Analysis of Models for E-Commerce Adoption Factors in Developing Countries. International Journal on Perceptive and Cognitive Computing 5: 72-80. [CrossRef]

Heredia-Calzado, Martha, and Antonio Duréndez. 2019. The Influence of Knowledge Management and Professionalization on the Use of Erp Systems and Its Effect on the Competitive Advantages of Smes. Enterprise Information Systems 13: 1245-74. [CrossRef]

Hussain, Arsalan, Arfan Shahzad, and Rohail Hassan. 2020. Organizational and Environmental Factors with the Mediating Role of E-Commerce and Sme Performance. Journal of Open Innovation: Technology, Market, and Complexity 6: 196. [CrossRef]

Hyung, L., and A. Dedahanov. 2014. Firm performance and entrepreneurial, market and technology orientations in korean technology intensive smes. Asian Social Science 10: 37. [CrossRef]

Jaworski, Bernard J., and Ajay K. Kohli. 1993. Market Orientation: Antecedents and Consequences. Journal of Marketing 57: 53-70. [CrossRef]

Kabir, Mohammed, Hazril Izwar Ibrahim, and Khairul Anuar Mohammad Shah. 2017. Entrepreneurial Competency as Determinant for Success of Female Entrepreneurs in Nigeria. Indonesian Journal of Business and Entrepreneurship (IJBE) 3: 143. [CrossRef] 
Kazmi, S. Kamal Hayder. 2017. Leather Industry Review. Available online: https:/ /www.pakistangulfeconomist.com/2017/12/25 /leather-industry-review / (accessed on 2 September 2021).

Khan, Muhammad Moutasim, and Tahir Ali. 2020. Impact of Production Cost and Product Value on the Exports of Pakistan Leather Footwear Industry. Journal of Engineering and Economic Development 6: 23-39.

Kiggundu, Moses N. 2002. Entrepreneurs and Entrepreneurship in Africa: What Is Known and What Needs to Be Done. Journal of Developmental Entrepreneurship 7: 239.

Kraemer, Kenneth L., Jennifer Gibbs, and Jason Dedrick. 2005. Impacts of Globalization on E-Commerce Use and Firm Performance: A Cross-Country Investigation. The Information Society 21: 323-40. [CrossRef]

Kumar, Ranjit. 2019. Research Methodology: A Step-by-Step Guide for Beginners. London: Sage Publications Limited.

Lawrence, Paul R., and Jay W. Lorsch. 1967. Organization and Environment. Cambridge: Harvard University Press, ISBN 9780875840642.

Lin, Boqiang, and Ranran Luan. 2020. Do Government Subsidies Promote Efficiency in Technological Innovation of China's Photovoltaic Enterprises? Journal of Cleaner Production 254: 120108. [CrossRef]

Man, Thomas W. Y., Theresa Lau, and Ed Snape. 2008. Entrepreneurial Competencies and the Performance of Small and Medium Enterprises: An Investigation through a Framework of Competitiveness. Journal of Small Business E Entrepreneurship 21: 257-76.

Manning, Stephan, Frank Boons, Oliver Von Hagen, and Juliane Reinecke. 2012. National Contexts Matter: The Co-Evolution of Sustainability Standards in Global Value Chains. Ecological Economics 83: 197-209. [CrossRef]

Merhi, Mohammad, and Punit Ahluwalia. 2017. Influence of Safety Nets, Uncertainty Avoidance, and Governments on E-Commerce Adoption: A Country-Level Analysis. Journal International Business Studies 35: 545-59.

Mohtaramzadeh, Masoumeh, T. Ramayah, and Cheah Jun-Hwa. 2018. B2b E-Commerce Adoption in Iranian Manufacturing Companies: Analyzing the Moderating Role of Organizational Culture. International Journal of Human-Computer Interaction 34: 621-39. [CrossRef]

Molla, Alemayehu, and Paul S. Licker. 2005. Ecommerce Adoption in Developing Countries: A Model and Instrument. Information E Management 42: 877-99.

Morgan, Krejcie. 2012. Sample Size Determination Using Krejcie and Morgan Table. Kenya: Kenya Projects Organization (KENPRO).

Nasuredin, Juzaimi, Azizi Haji Halipah, and Abdul Shukor Shamsudin. 2016. Entrepreneurial Competency and Smes Performance in Malaysia: Dynamic Capabilities as Mediator. International Journal of Research 3: 4759-70.

Oliveira, Tiago, and Maria Fraga Martins. 2010a. Understanding E-Business Adoption across Industries in European Countries. Industrial Management \& Data Systems 110: 1337-54.

Oliveira, Tiago, and Maria Fraga Martins. 2010b. Information Technology Adoption Models at Firm Level: Review of Literature. In The European Conference on Information Systems Management. Reading: Academic Conferences International Limited.

Pakistan Bureau of Statistics. 2019. Available online: http:/ / www.pbs.gov.pk/publications (accessed on 2 September 2021).

PTA. 2015. Pakistan Tanners Association Annual Report 2015-2016. Available online: https:/ /www.pakistantanners.org/documents / pta_annual_report_2010_2011.pdf (accessed on 2 September 2021).

Qureshi, Muhammad Azeem, Minhas Akbar, Ahsan Akbar, and Petra Poulova. 2021. Do Esg Endeavors Assist Firms in Achieving Superior Financial Performance? A Case of 100 Best Corporate Citizens. SAGE Open 11: 21582440211021598. [CrossRef]

Rajan, Madhav V., Stefan Reichelstein, and Mark T. Soliman. 2007. Conservatism, Growth, and Return on Investment. Review of Accounting Studies 12: 325-70. [CrossRef]

Raza, Saqlqin, Mohd Sobri Minai, and Noor Azmi Hashim. 2017. The Conceptual Framework in Examining the Influence of Relationship Competency on Small Firm Performance with the Mediating Role of Dynamic Capabilities. Journal of Business Management and Accounting (JBMA) 7: 85-100.

Sarstedt, Marko, Christian M. Ringle, and Joseph F. Hair. 2017. Partial Least Squares Structural Equation Modeling. Handbook of Market Research 26: 1-40.

Shahzad, Arfan, Hon Keong Chin, Mohsin Altaf, and Farooq Anwar Bajwa. 2020. Malaysian Sme's Performance and the Use of E-Commerce: A Multi-Group Analysis of Click-and-Mortar and Pure-Play E-Retailers. Pakistan Journal of Commerce and Social Sciences (PJCSS) 14: 1-33.

Shanmugam, Jaya Kumar. 2016. The Impact of Information Technology (It) Adoption Towards Small Medium Enterprises (Smes) Performance in Malaysia. Malaysia: The Role of It Governance as Moderator.

Sheikh, Adnan Ahmed, Naeem Ahmad Rana, Aneeq Inam, Arfan Shahzad, and Hayat Muhammad Awan. 2018. Is E-Marketing a Source of Sustainable Business Performance? Predicting the Role of Top Management Support with Various Interaction Factors. Cogent Business \& Management 5: 1516487.

Sila, Ismail. 2010. Do Organisational and Environmental Factors Moderate the Effects of Internet-Based Inter organizational Systems on Firm Performance? European Journal of Information Systems 19: 581-600. [CrossRef]

SMEDA. 2018. State of SMES in Pakistan. Available online: https:/ / smeda.org/index.php?option=com_content\&view=article\&id=7: state-of-smes-in-pakistan\&catid $=15$ (accessed on 1 September 2021).

Soliman, Khalid S., and Brian D. Janz. 2004. An Exploratory Study to Identify the Critical Factors Affecting the Decision to Establish Internet-Based Interorganizational Information Systems. Information \& Management 41: 697-706.

Sunayana, K., and Rakhshanda Parveen. 2019. The Impact of E-Commerce on Organizational Performance of the Indian Travel Agencies. Paper presented at the TISC-Tourism International Scientific Conference, Vrnjačka Banja, Serbia, May 30-June 1. 
Tehseen, Shehnaz, and T. Ramayah. 2015. Entrepreneurial Competencies and Smes Business Success: The Contingent Role of External Integration. Mediterranean Journal of Social Sciences 6: 50. [CrossRef]

Teo, Thompson S. H., and Chandrasekaran Ranganathan. 2004. Adopters and Non-Adopters of Business-to-Business Electronic Commerce in Singapore. Information \& Management 42: 89-102.

The Financial Daily. 2018. Pakistan Surgical Instrument Industry. The Financial Daily. Available online: https://www.pressreader. com/pakistan/the-financial-daily/20180724/281603831258792 (accessed on 8 September 2021).

Wardoyo, Dewie Tri Wijayati, Sri Setyo Iriani, and Achmad Kautsar. 2018. Adoption of E-Commerce, Entrepreneurship Orientation Mediated by Business Strategy on the Performance Food Industries. Technology 9: 896-902.

Wymer, Scott. A., and Elizabeth. A. Regan. 2015. Electronic Markets. Factors Influencing E-Commerce Adoption and the Use of Small and Medium Businesses 15: 438-53.

Yadegaridehkordi, Elaheh, Mehrbakhsh Nilashi, Liyana Shuib, Mohd Hairul Nizam Bin Md Nasir, Shahla Asadi, Sarminah Samadf, and Nor Fatimah Awang. 2020. The Impact of Big Data on Firm Performance in Hotel Industry. Electronic Commerce Research and Applications 40: 100921. [CrossRef]

Zain, Mohamed, Raduan Che Rose, Iskandar Abdullah, and Maslin Masrom. 2005. The Relationship between Information Technology Acceptance and Organizational Agility in Malaysia. Information \& Management 42: 829-39.

Zhu, Kevin, and Kenneth L. Kraemer. 2005. Post-Adoption Variations in Usage and Value of E-Business by Organizations: CrossCountry Evidence from the Retail Industry. Information Systems Research 16: 61-84. [CrossRef]

Zhu, Kevin, Kenneth Kraemer, and Sean Xu. 2003. Electronic Business Adoption by European Firms: A Cross-Country Assessment of the Facilitators and Inhibitors. European Journal of Information Systems 12: 251-68. [CrossRef]

Zhu, Kevin, Kenneth L. Kraemer, and Sean Xu. 2006. The Process of Innovation Assimilation by Firms in Different Countries: A Technology Diffusion Perspective on E-Business. Management Science 52: 1557-76. [CrossRef] 